Revista Destaques Acadêmicos, Lajeado, v. 12, n. 3, 2020. ISSN 2176-3070

DOI: http://dx.doi.org/10.22410/issn.2176-3070.v12i3a2020.2654

http://www.univates.br/revistas

\title{
CUIDADO DE ENFERMAGEM NA ATENÇÃO PRIMÁRIA À CRIANÇA COM SÍNDROME DE WILLIAMS-BEUREN: UMA REVISÃO INTEGRATIVA
}

Alessandra Moreira Nonato ${ }^{1}$, Amanda Klodzinski ${ }^{1}$, Ana Clara Nadalin ${ }^{1}$, Ana Lígia Feriato ${ }^{1}$, Anna Luiza de Camargo Cenzi ${ }^{1}$, Ana Paula de Miranda Vargas ${ }^{1}$, Carolaine das Graças Marcon Gumildes ${ }^{1}$, Cassiana Pinheiro Ricardo ${ }^{1}$, Victoria Isabella Nakaba Soster ${ }^{1}$, Karin Rosa Persegona Ogradowski², Débora Maria Vargas Makuch ${ }^{3}$, Juliana Ollé Mendes ${ }^{3}$

RESUMO: O presente artigo trata-se de uma revisão integrativa tendo como objetivos conhecer a fisiopatologia da síndrome de Williams-Beuren e suas consequências no atraso psicomotor da criança e elaborar um plano de cuidados com base nos diagnósticos reais e potenciais elencados baseando-se na taxonomia NANDA 2018-2020, a partir da emergência do tema numa realidade de atenção primária de Curitiba, vivenciada por acadêmicas de enfermagem, por meio da metodologia da problematização, utilizando o Arco de Maguerez, aplicado a um caso fictício. Para a teorização, realizada busca em base de dados, sendo eleitas BVS, Pubmed e Scielo, resultando no total de 27 artigos. A partir do esclarecimento da complexidade cromossômica envolvida na síndrome e as complicações decorrentes da expressividade dessa alteração, compreende-se que a atuação de enfermagem na atenção primária frente à Síndrome de Williams-Beuren aborda integralmente a criança desde seu nascimento e contínuo acompanhamento do desenvolvimento ao longo da vida, pois por meio da monitorização, faz-se possível a prevenção, identificação e intervenção diante das complicações inerentes à síndrome.

Palavras-chave: Síndrome de Williams Beuren. Estenose aórtica supravalvar. Hipertensão Pulmonar. Atraso no desenvolvimento.

1 Acadêmicas de Enfermagem do $5^{\circ}$ Período do Curso de Graduação em Enfermagem da Faculdades Pequeno Príncipe.

2 Coordenadora do Curso de Graduação em Enfermagem da Faculdades Pequeno Príncipe.

3 Docentes do Curso de Graduação em Enfermagem da Faculdades Pequeno Príncipe. 


\section{INTRODUÇÃO}

Com o desenvolvimento da medicina e de novas técnicas de diagnósticos, muitas síndromes raras, que antes eram desconhecidas, começaram a ser identificadas, estudadas e tendo suas etiologias definidas. Dentre elas, é possível citar a Síndrome de Williams, também chamada de Williams-Beuren, que é um distúrbio raro descrito pela primeira vez em 1961 na Nova Zelândia, o qual afeta o cromossomo 7 na região 7q11.23 (OSÓRIO et al., 2016).

Sua prevalência é baixa, variando de $1 \mathrm{em} 7.500$ a 1 em 20.000 nascidos vivos, tendo como consequência a alteração de 24 a 28 genes, atribuindo à criança características faciais distintas, alterações cardíacas e/ou pulmonares, afetando o desenvolvimento infantil (YAO et al., 2019).

Este estudo tem como objetivos conhecer a fisiopatologia da síndrome de Williams-Beuren e suas consequências no atraso psicomotor da criança e elaborar um plano de cuidados com base nos diagnósticos reais e potenciais elencados baseando-se na taxonomia NANDA 2018-2020 (NANDA INTERNATIONAL, 2018).

\section{MÉTODO}

Para realização deste estudo utilizou-se a Metodologia da Problematização, por meio das etapas do Arco de Maguerez - Observação da Realidade, Pontos-Chave, Teorização, Hipóteses de Solução e Aplicação à Realidade (PRADO et al., 2012), articulada ao método de Revisão Integrativa (RI), segundo Mendes, Silveira e Galvão (2019).

O método de Revisão Integrativa permite a síntese de conhecimento por meio de processo sistemático e rigoroso. A condução de RI deve pautar-se nos mesmos princípios preconizados de rigor metodológico no desenvolvimento de pesquisas (MENDES, SILVEIRA e GALVÃO, 2019).

As etapas deste método são: 1) elaboração da pergunta da revisão; 2) busca e seleção dos estudos primários; 3) extração de dados dos estudos; 4) avaliação crítica dos estudos primários incluídos na revisão; 5) síntese dos resultados da revisão e 6) apresentação do método. A importância do rigor metodológico na RI e a necessidade de uso de ferramentas para gerenciar a seleção dos estudos primários foram os aspectos considerados para a construção da presente reflexão para os pesquisadores da área da saúde (MENDES, SILVEIRA e GALVÃO, 2019).

Este estudo foi construído a partir da experiência vivida por acadêmicas de Enfermagem do quinto período, de uma instituição de ensino superior privada, localizada na região sul do Brasil, durante o ensino clínico de Puericultura, entre março e abril de 2020. A particularidade deste período da formação está na aproximação do estudante de Enfermagem com a 
especialidade da Pediatria, articulada à disciplina de Genética, o que instigou o desenvolvimento de estudos relacionados a Síndrome de Williams.

Percorrendo as etapas do Arco de Maguerez, apresenta-se aqui o caso fictício que norteou este trabalho:

M.T., 5 meses, gemelar de S.T., chega a Unidade Básica de Saúde acompanhada de sua mãe, para consulta de Puericultura. Mãe relata preocupação com o desenvolvimento de M.T. comparado a S.T., referindo diagnóstico de Sindrome de Williams para M.T., identificada logo após o nascimento. Mãe refere que M.T. não apresenta a mesma sustentação corporal e tem reações bruscas a estímulos comparados a S.T. A paciente possui alteração cromossômica caracterizada pela Sindrome de Williams Beuren, apresenta atraso motor, hipertensão pulmonar e histórico de estenose pulmonar. Realiza acompanhamento com as especialidades: neurologia, cardiologia, nefrologia e endocrinologia.

Deste caso emergiu a seguinte questão norteadora: Quais as ações de enfermagem frente a uma criança com Síndrome de Williams-Beuren?

Para responder à questão de pesquisa, foram elencados os seguintes Pontos-Chave: síndrome de Williams Beuren; estenose aórtica supravalvular; hipertensão pulmonar e atraso no desenvolvimento.

\section{RESULTADOS}

As bases de dados escolhidas para a busca de artigos foram a Biblioteca Virtual em Saúde (BVS), PubMed e SciELO. Como critérios de inclusão: artigos disponíveis, relacionados ao tema, nos idiomas inglês, português e espanhol, e abrangendo um período de publicação entre Janeiro de 2015 a março de 2020.

Os critérios de exclusão utilizados foram: Teses e Dissertações, artigos não disponíveis, outros idiomas que não os definidos, período anterior a 2015 e posterior a março de 2020, artigos redundantes e não relacionados ao tema.

A busca de artigos foi realizada no dia 25/03/2020, utilizando os descritores: "Síndrome de Williams-Beuren", "Estenose aórtica supravalvular", "Hipertensão Pulmonar" e "Atraso no desenvolvimento". A Figura 1 representa o fluxograma de identificação e seleção dos artigos para a revisão integrativa. 
Figura 1- Fluxograma de identificação e seleção dos artigos para a revisão integrativa

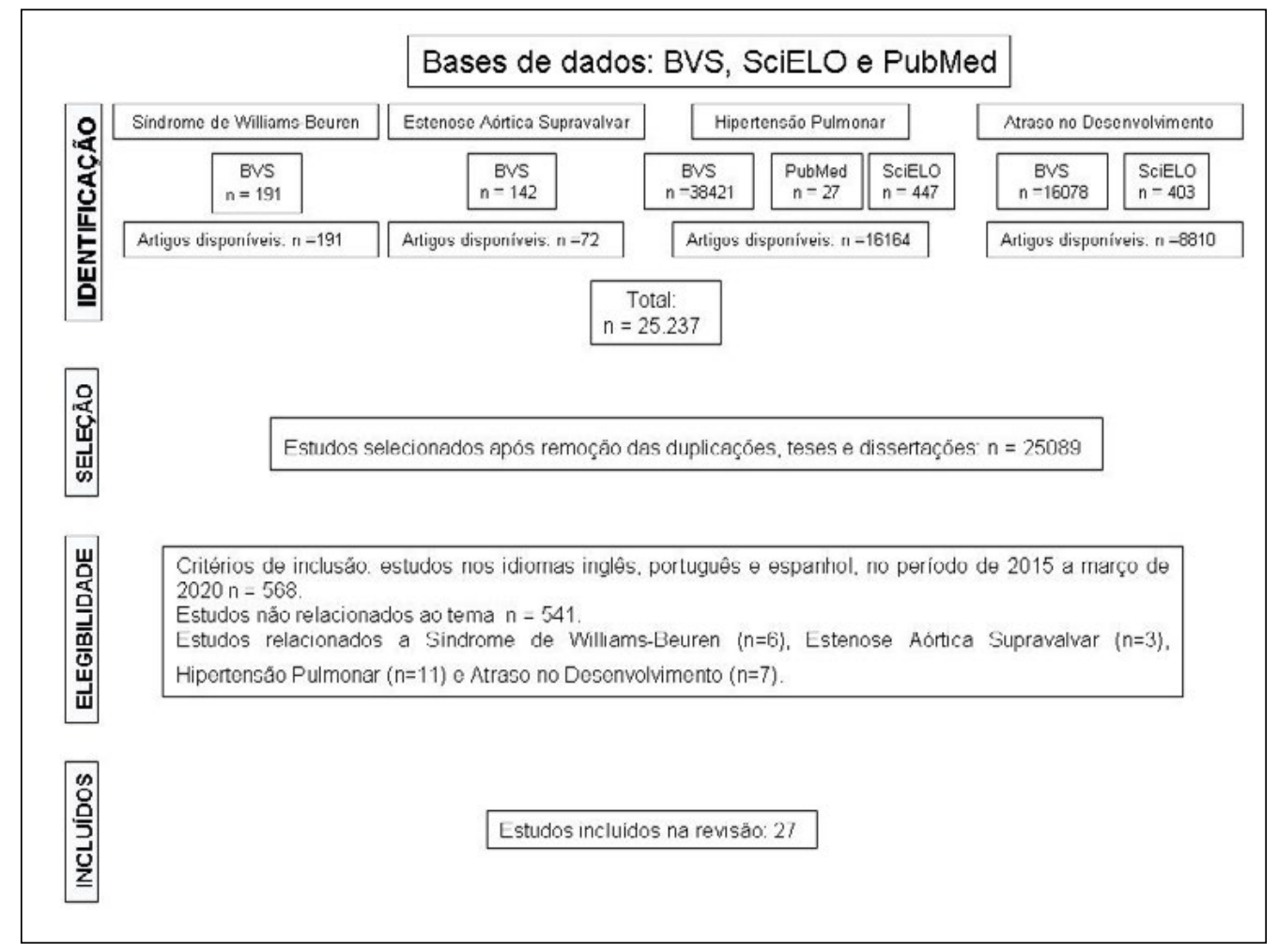

Fonte: Dados do estudo (2020).

Após efetivação das estratégias de busca, para este estudo foram selecionados 27 artigos. Para auxiliar na análise dos estudos capturados, foi elaborado um quadro contendo dados relacionados ao ano de publicação, autores, metodologia utilizada nas pesquisas, participantes, resultados e recomendações dos estudos. A análise destes dados deu-se por meio de estatística simples, por cálculo de proporção.

Após a leitura e primeira análise dos artigos selecionados foi possível levantar que, quanto ao recorte temporal utilizado, $4(14,9 \%)$ dos estudos capturados foram publicados no ano de 2015, 8 (29,7\%) no ano de 2016, 5 $(18,5 \%)$ no ano de 2017, $5(18,5 \%)$ no ano de 2018 e $5(18,5 \%)$ no ano de 2019. (TABELA 1). 
Tabela 1 - Distribuição da amostra dos artigos selecionados quanto ao ano de publicação

\begin{tabular}{c|c|c}
\hline ANO & N & \% \\
\hline 2019 & 5 & 18,5 \\
\hline 2018 & 5 & 18,5 \\
\hline 2017 & 5 & 18,5 \\
\hline 2016 & 8 & 29,7 \\
\hline 2015 & 4 & 14,9 \\
\hline Total & $\mathbf{2 7}$ & $\mathbf{1 0 0}$ \\
\hline
\end{tabular}

Fonte: Dados do estudo (2020).

Quanto ao idioma, 7(26\%) dos estudos capturados foram publicados no idioma português e 20 (74\%) em inglês (TABELA 2).

Tabela 2 - Distribuição da amostra dos artigos selecionados quanto ao idioma

\begin{tabular}{l|c|c}
\hline \multicolumn{1}{c|}{ ANO } & N & \% \\
\hline Português & 7 & 26 \\
\hline Inglês & 20 & 74 \\
\hline Total & $\mathbf{2 7}$ & $\mathbf{1 0 0}$ \\
\hline
\end{tabular}

Fonte: Dados do estudo (2020).

\section{DISCUSSÃO}

A Síndrome de Williams (WS) é um distúrbio raro causado por uma microdeleção heterozigótica no cromossomo 7, região 7q11.23, tendo alterações de 24 a 28 genes, responsáveis pelas alterações sistêmicas características estenose aórtica supravalvar, estenose pulmonar, características específicas da aparência, retardo de crescimento, podem apresentar hipercalcemia infantil, anormalidades do tecido conjuntivo, retardo no crescimento incluindo hipotonia muscular - deficiência intelectual, dismorfismo e um fenótipo neurocomportamental distinto, apresentando também atraso no desenvolvimento neuropsicomotor, e um comportamento excessivamente amigável (GHAFFARI et al., 2018; YAO et al., 2019) -, com uma estimativa de prevalência de 1 em 7500 e 1 em 20.000 nascidos vivos (BARAK et al., 2019; OSÓRIO et al., 2016).

Assim, como sugere Barak et al. (2019), a hipersociabilidade característica do indivíduo com WS, pode estar relacionada com a deleção seletiva do gene Gtf2i da região cromossômica em questão que codifica o fator IIi, que colabora com a transcrição e expressão de genes de forma variável, atuando principalmente sobre a remodelação da cromatina. Nas células nervosas do córtex pré-frontal, 
essa deleção (total ou parcial) causa defeitos neuroanatômicos que consistem em redução do número de oligodendrócitos maduros, afinamento da bainha de mielina e alteração na condução axonal do impulso elétrico, resultando na existência dos padrões de comportamento hipersociáveis, distúrbios dos movimentos motores finos e tendência à ansiedade relacionada às fobias específicas.

Ainda, tais alterações comportamentais e motoras podem ser amenizadas com tratamentos na linha de melhoramento da condução axonal do impulso nervoso através de fármacos bloqueadores seletivos dos canais de potássio e/ou drogas remielinizadoras (BARAK et al., 2019). As características faciais observadas nesses pacientes são: ponta nasal bulbosa, um padrão estrelado da íris, um filtro longo, uma boca larga, anomalias dentárias e estreitamento bitemporal, orelha proeminente, maxilar pequeno, inchaço de pálpebras (GHAFFARI et al., 2018; YAO et al., 2019).

A síndrome é conhecida por suas habilidades cognitivas desiguais, dentre elas a dificuldade na cognição visuoespacial embora haja algumas diferenças fenotípicas interindividuais. Em estudos foi proposto que,

[...] a dificuldade na cognição visuoespacial dos pacientes com WS pode ser atribuído à haploinsuficiência de alguns genes localizados na região deletada no 7q11.23, com base em um exame de deleções atípicas identificadas em pacientes com WS com déficits cognitivos atípicos. De acordo com essa hipótese, o índice interindividual sugere diferenças na capacidade cognitiva visuoespacial surgem de variações na deleção (MURAMATSU et al., 2016, p. 7).

A capacidade visuoespacial refere-se à capacidade de gerar, reter, recuperar e transformar aquilo que foi visto, envolve o armazenamento e processamento da informação visual e espacial do ambiente, ou seja, consiste na capacidade de ver partes de um objeto e depois reconstituí-lo com base na interpretação das peças, desse modo a capacidade de construção visuoespacial é considerado uma das habilidades visoespaciais. E nos indivíduos com a WS tal capacidade pode variar amplamente de paciente para paciente e o grau de desenvolvimento cognitivo. (MURAMATSU et al., 2017).

Segundo Yao et al. (2019), os parâmetros avaliados de peso, altura e desenvolvimento físico em crianças e adolescentes com WS foi estatisticamente significante quando comparado com o grupo de controle do estudo, pois os resultados indicam que crianças com WS têm atraso no crescimento na primeira infância e na infância, ficando para trás das crianças saudáveis no grupo controle desde o nascimento em termos de peso, e essa diferença se torna a mais significativa dentro do intervalo de 6 a 18 meses. Portanto para um diagnóstico precoce é necessário o acompanhamento e triagem da criança desde o nascimento, pois as características faciais distintas, e sua incrível capacidade de socialização só se manifestam com a idade, desse modo é necessário 
estar atento ao crescimento físico lento, bem como alterações cardíacas e/ou pulmonares.

Somado ainda às questões genotípicas, o estudo de Guenat et al. (2017) sugere que pacientes que possuem WS possam ter uma suscetibilidade maior ao linfoma não Hodgkin por combinações de danos ao DNA devido à expressão genética. Contudo, o estudo não foi conclusivo para entender a suscetibilidade ao linfoma não Hodgkin, e segundo os autores, são necessários estudos mais incisivos em cima dessa teoria.

Dentre as alterações cardíacas desencadeadas pela WS, a estenose aórtica supravalvar (EAS), é a forma menos comum de obstrução da via de saída do ventrículo esquerdo e representa $0,05 \%$ de todas as cardiopatias congênitas, acometendo cerca de $70 \%$ dos casos da síndrome. Caracteriza-se como uma obstrução congênita da aorta ascendente, mais comumente envolvendo a junção sinotubular, podendo ocorrer como uma dismorfia semelhante a um "relógio de areia" ou como uma hipoplasia difusa. Essa malformação pode ocorrer como um aspecto da síndrome de Williams, sendo o defeito cardíaco mais frequente, uma forma familiar hereditária autossômica dominante não associada à WS, podendo ocorrer em pacientes sem história familiar e pacientes com hipercolesterolemia homozigótica familiar, ocorrendo em até $44 \%$ dos casos neste quadro (SZAFLIK et al., 2016).

As principais características clínicas da EAS são síncope, dispneia e palpitações e a incidência desses sintomas é tão precoce quanto a progressão da doença. Em geral, essa doença é mais comumente diagnosticada na criança, devido à presença de sopro relacionado à obstrução. A presença de adultos portadores de EAS não tratada é ainda mais comum, isto ocorre devido a não detecção da doença ou imprecisão diagnóstica. Algumas doenças associadas, como coarctação da aorta e malformações dos grandes vasos da base, podem contribuir para dúvidas ou erros diagnósticos que, muitas vezes, postergam o tratamento definitivo adequado (YILDIZ et al., 2015).

Visivelmente é possível encontrar uma forma esporádica da estenose aórtica supravalvar com aparência facial característica (fronte alta e ampla, hipertelorismo, estrabismo, nariz arrebitado, filtro longo, boca larga, anormalidades dentárias, bochechas salientes, micrognatia e orelhas com implantação baixa). Quando associada à hipercalcemia idiopática da infância, essa forma é conhecida como síndrome de Williams. Os sintomas cardeais são, a síncope e a insuficiência cardíaca, especialmente a dispneia aos esforços. Uma complicação incomum, porém, catastrófica, é a morte súbita (SZAFLIK et al., 2016).

Sendo o sopro tão alto e com irradiação tão ampla, é frequentemente audível ao nível do ápice, levantando a dúvida da presença concomitante de regurgitação mitral. Vários aspectos podem ajudar a distinguir os dois sopros. Mesmo quando audível no ápice, o sopro da estenose aórtica supravalvar mantém a sua localização durante o período de ejeção, ao passo que o da 
regurgitação mitral é holossistólico. Portanto, na ausculta cardíaca identificase $\mathrm{B}^{2}$ como atrasado, pois sua valva se fecha posteriormente, assim como o frêmito sistólico que corresponde como o sopro da estenose, caracterizado como qualidade áspera ou rangente. O comportamento do sopro em presença de extra-sístoles pode ajudar muito (SZAFLIK et al., 2016).

Destaca ainda que, na estenose aórtica, o sopro diminui consideravelmente e pode até mesmo desaparecer com uma extrasístole. No primeiro batimento após a pausa compensatória, o aumento pós-extrassistólico da contração ventricular esquerda identifica marcadamente o sopro. $\mathrm{Na}$ regurgitação mitral, em contrapartida, o sopro permanece relativamente inalterado em intensidade, tanto no batimento extrassistólico quanto no que ocorre após a pausa compensatória. Do mesmo modo, se existe uma grande variação na duração do ciclo cardíaco, de batimento para batimento ( $\mathrm{p}$. ex.: como na fibrilação atrial), o sopro da estenose aórtica supravalvar varia bastante de intensidade ao passo que o da regurgitação mitral permanece com a sua intensidade relativamente constante.

A investigação diagnóstica é feita com exames como a ecocardiografia, radiografia de tórax, ressonância magnética, dentre outros. Os resultados obtidos, na maioria das vezes, incluem a identificação do aumento discreto da área cardíaca, sobrecarregando o ventrículo esquerdo pela radiografia; na ecocardiografia se evidenciam os calibres das artérias pulmonares menores que $29 \mathrm{~mm}$ (FRICKE et al., 2015).

O prognóstico da EAS vem sofrendo grandes mudanças nestes últimos anos, pela possibilidade de alternativas terapêuticas, como valvuloplastia percutânea com cateter balão, método efetivo na abolição do gradiente entre o ventrículo esquerdo e a aorta em crianças, ou até mesmo o transplante cardíaco, ou o procedimento de Norwood ("sacrifício do ventrículo esquerdo, passando o ventrículo direito a assumir a circulação sistêmica) (YILDIZ et al., 2015).

Comumente associada à doença cardíaca esquerda e doença pulmonar, a Hipertensão pulmonar (HP) é caracterizada por um grupo de doenças progressivas tendo como característica o aumento na resistência pulmonar, levando à falência ventricular direita, e como consequência à morte prematura. A HP é relacionada a desfechos desfavoráveis nos pós-operatórios imediato e tardio. (CRUZ et al., 2019; SANTOS et al., 2018).

Desde 1973, considerava-se arbitrariamente HP quando a pressão de artéria pulmonar média (PAPm) era igual ou superior a $25 \mathrm{mmHg}$. Entretanto, dados recentes mostram que, mesmo com valores inferiores de PAPm, existe aumento da mortalidade. Dessa forma, em dezembro de 2018 foi publicado o consenso resultante do 6-o Simpósio Mundial de Hipertensão Pulmonar, redefinindo HP para a situação na qual a PAPm é superior a $20 \mathrm{mmHg}$ e a resistência vascular pulmonar maior ou igual a 3 unidades Wood (CALDERARO et al., 2019). 
Segundo Belo, Oselame e Neves (2016), a criança portadora de cardiopatia congênita, normalmente, encontra-se abaixo do peso e altura estipulados como ideais pela OMS. Ainda, a HP apareceu em quase $25 \%$ dos casos, no entanto, não é mencionada dentre os diagnósticos mais comuns na bibliografia especializada.

As divisões classificativas da HP são correspondentes às etiologias de base: classe I, idiopática; classe II, associada a doenças do coração esquerdo; classe III, associada a doenças pulmonares; classe IV, associada a tromboembolismo pulmonar; e classe V, multifatorial (PAZELLO e CAMAROZANO, 2018).

A deficiência causada pela HP é multifatorial, e depende de fatores como capacidade reduzida de se exercitar, limitação funcional, mecanismos fisiológicos compensatórios, impacto psicológico da doença, assim como os efeitos adversos dos remédios e o custo do tratamento (REIS et al., 2019).

No acompanhamento de pacientes com hipertensão pulmonar, diversos aspectos são norteadores de decisões terapêuticas e determinantes do prognóstico (TORRES et al., 2015). Nos últimos anos, vários biomarcadores da HP foram investigados com o intuito de buscar um método eficiente e não invasivo de estratificação e monitorização (PLÁCIDO et al., 2017). Nos anos 1970, a oxigenação por membrana extracorpórea foi usada para administrar a insuficiência respiratória e a hipertensão pulmonar e, de certa forma, posteriormente para assistência cardíaca ventricular (KATTAN et al., 2017).

Segundo Pazello e Camarozano (2018), o método atual de escolha para acompanhamento da HP usado de rotina nos ambulatórios é o exame de ecocardiografia transtorácica. A ecocardiografia é uma ferramenta confiável, não invasiva, para detecção e acompanhamento da pressão arterial pulmonar. De acordo com Alkholy et al. (2019), como a HP é uma doença progressiva, irreversível com risco de morte, há urgência de uma ferramenta fácil, disponível e subjetiva para avaliar o risco e a progressão individualizados da HP em crianças.

Assim, é importante a identificação precoce dos pacientes com risco de desenvolver HP, já que ela está diretamente relacionada ao prognóstico, devido à reversibilidade potencial do quadro quando a indicação cirúrgica corretiva e/ou o tratamento medicamentoso se fazem em tempo adequado (LIMA et al., 2017).

Retomando o caso norteador deste estudo, a criança com WS apresenta déficit para adquirir determinadas competências de acordo com sua idade, $\mathrm{o}$ que caracteriza o atraso do desenvolvimento neuropsicomotor (ADNPM). Este termo, geralmente, é utilizado temporariamente e restringe-se aos primeiros cinco anos de vida, utilizado até chegar a uma classificação diagnóstica objetiva, definindo o que levou a ocorrência do atraso (DORNELAS e MAGALHAES 2016). 
O desenvolvimento neuropsicomotor (DNPM) é um processo sequencial, contínuo, sendo o desenvolvimento infantil, um processo dinâmico e complexo, que promove mudanças e evoluções. Está relacionado à idade cronológica pela qual o ser humano adquire habilidades nas áreas de motricidade finaadaptativa e ampla, pessoal-social e linguagem, iniciando na fase intrauterina envolvendo o crescimento físico, maturação neurológica, motora, cognitiva, comportamental da criança e também sofre influências de diversos fatores biológicos e ambientais. É essencial o monitoramento do DNPM, permitindo a detecção de fatores de risco - como sexo, fatores genéticos, habilidades da criança, baixo nível socioeconômico, características familiares, apoio social - e assim, as estimulações precoces (COELHO et al., 2016; MATOS, CAVALCANTE e COSTA, 2016; SOARES et al., 2017).

Logo, avaliar esse processo é uma tarefa complexa que exige uma observação atenta e continuada nos primeiros anos de vida e conhecimento de todas as etapas do desenvolvimento, visando detectar precocemente os possíveis desvios. É importante contar com a família nesse momento para recolher informações pertinentes e auxiliar a propiciar um ambiente oportuno para o crescimento da criança, principalmente nos primeiros anos de vida. A escola também exerce um papel muito importante e interfere diretamente nas fases do desenvolvimento, por propiciar constantes interações e trocas sociais, devendo atentar-se ao oferecer um ambiente pouco estimulador e cuidado ineficaz à criança (COELHO et al., 2016; CORREA, MINETTO e CREPALDI, 2018).

Esses atrasos estão diretamente relacionados aos fatores biológicos, culturais, familiares e ambientais, os quais exercem influências sobre o desenvolvimento de aptidões linguísticas, cognitivas, motoras e sociais da criança. A classificação vai desde leve, moderado, até o atraso grave, sendo a investigação, observação e escuta ativa pontos importantes para o diagnóstico (CORREA, MINETTO e CREPALDI, 2018; DORNELAS e MAGALHAES, 2016).

Estudos apontam que crianças de alto risco têm maior propensão a apresentar um ADNPM, especialmente no domínio linguagem, indicando relação direta com a baixa escolaridade materna, relação monoparental e intercorrências neonatais. Além disso, o ambiente em que a criança vive, principalmente, no que diz respeito à receptividade dos pais está diretamente relacionado ao desenvolvimento típico (ZAGO et al., 2017).

Segundo Coelho et al. (2016), a Academia Americana de Pediatria recomenda aplicar um instrumento padronizado de triagem durante os três primeiros anos de vida, independentemente de a criança apresentar ou não de fatores de risco, visando aumentar a detecção e a intervenção precoce de possíveis atrasos, sendo um dos objetivos das consultas pediátricas de rotina. O programa de Atenção Integrada a Doenças Prevalentes na Infância (AIDPI), desenvolvido pela Organização Mundial de Saúde (OMS) e pelo Fundo das Nações Unidas para a Infância e a Adolescência (Unicef), serviu de base 
para a elaboração de uma tabela de vigilância do desenvolvimento adaptada e usada na Caderneta de Saúde da Criança na rede de atenção primária. Entretanto, pela ausência de um instrumento padronizado para a avaliação do desenvolvimento infantil no Brasil que seja utilizado na rede pública e privada concomitantemente, os atrasos acabam sendo identificados tardiamente, muitas vezes após o ingresso da criança nos anos iniciais do ensino fundamental. Este cenário leva a tratamentos mais longos e, talvez, permanentes, além do aumento de custos em avaliações especializadas e exames, e da apreensão familiar (CORREA, MINETTO e CREPALDI, 2018).

Os fatores de proteção ao serem elencados, identificados e implantados podem alterar ou transformar condições de risco no ambiente, onde é necessário estabelecer uma rede de apoio de atenção e proteção ao desenvolvimento da criança, buscando identificar os fatores de risco, compreender a criança, a sua família e o próprio contexto em que estão inseridos. Afinal, os fatores de risco para o atraso são múltiplos e o acúmulo de condições pode determinar maior impacto no desenvolvimento da criança (DORNELAS e MAGALHAES 2016).

A assistência à saúde da criança é uma atividade de fundamental importância em função da vulnerabilidade nessa fase do ciclo de vida. Por meio do acompanhamento da criança na puericultura, espera-se reduzir a incidência de doenças, promovendo sua saúde de modo que esta possa crescer e desenvolver-se para alcançar todo seu potencial (SILVA et al., 2017).

Como resultado do aprofundamento nas peculiaridades da síndrome, e apreensão da necessidade de um cuidado sistematizado e individualizado pelo enfermeiro e equipe interdisciplinar, elaborou-se um Plano de Cuidados, a partir de Diagnósticos de Enfermagem com base na Taxonomia NANDA 20182020 (NANDA INTERNATIONAL, 2018), contemplando as etapas de Hipóteses de solução e Aplicação à Realidade, do Arco de Maguerez (QUADRO 1).

Quadro 1-Plano de Cuidados à criança com Síndrome de Williams-Beuren.

\begin{tabular}{|c|c|c|c|c|}
\hline Classe & Diagnóstico & $\begin{array}{c}\text { Fator } \\
\text { relacionado/ } \\
\text { de risco }\end{array}$ & $\begin{array}{c}\text { Característica } \\
\text { definidora }\end{array}$ & Prescrição de Enfermagem \\
\hline $\begin{array}{c}\text { Função } \\
\text { Respiratória. }\end{array}$ & $\begin{array}{c}\text { Troca de gases } \\
\text { prejudicada. }\end{array}$ & $\begin{array}{c}\text { Relacionado } \\
\text { à presença } \\
\text { de estenose } \\
\text { aórtica } \\
\text { supravalvar. }\end{array}$ & $\begin{array}{c}\text { Evidenciado } \\
\text { por padrão } \\
\text { respiratório } \\
\text { anormal. }\end{array}$ & $\begin{array}{c}\text { 1. Sugerir manter criança em } \\
\text { posições anatômicas que } \\
\text { favoreçam a expansão torácica, } \\
\text { inclusive para dormir, como } \\
\text { Fowler ou Semi Fowler. }\end{array}$ \\
\hline
\end{tabular}




\begin{tabular}{|c|c|c|c|c|}
\hline $\begin{array}{l}\text { Percepção } \\
\text { da saúde. }\end{array}$ & $\begin{array}{l}\text { Envolvimento } \\
\text { de atividades } \\
\text { de recreação } \\
\text { diminuído. }\end{array}$ & $\begin{array}{c}\text { Relacionado } \\
\text { à } \\
\text { mobilidade } \\
\text { prejudicada. }\end{array}$ & $\begin{array}{l}\text { Evidenciado } \\
\text { por } \\
\text { sustentação } \\
\text { corporal } \\
\text { diminuída. }\end{array}$ & $\begin{array}{l}\text { 1. Comunicar o centro de } \\
\text { educação sobre a limitação; } \\
\text { 2. Sugerir instalação de } \\
\text { barras de apoio em locais } \\
\text { potencialmente perigosos } \\
\text { do domicílio com rampas, } \\
\text { escadas e banheiros; } \\
\text { 3. Orientar sobre maior } \\
\text { cautela e necessidade } \\
\text { de acompanhamento e } \\
\text { observação constante durante } \\
\text { atividades que envolvam } \\
\text { corrida ou outros movimentos } \\
\text { bruscos. }\end{array}$ \\
\hline Hidratação. & $\begin{array}{l}\text { Risco de } \\
\text { desequilíbrio } \\
\text { eletrolítico. }\end{array}$ & $\begin{array}{l}\text { Relacionado } \\
\text { à disfunção } \\
\text { renal. }\end{array}$ & & $\begin{array}{l}\text { 1. Orientar preferência por } \\
\text { ingesta hídrica à base de água } \\
\text { filtrada ou fervida e sucos com } \\
\text { menor concentração de sais } \\
\text { minerais. }\end{array}$ \\
\hline $\begin{array}{l}\text { Conforto } \\
\text { físico. }\end{array}$ & $\begin{array}{l}\text { Conforto } \\
\text { prejudicado. }\end{array}$ & $\begin{array}{l}\text { Relacionado } \\
\text { aos sintomas } \\
\text { da doença. }\end{array}$ & $\begin{array}{l}\text { Evidenciado } \\
\text { por alteração } \\
\text { no padrão de } \\
\text { sono. }\end{array}$ & $\begin{array}{l}\text { 1. Sugerir estabelecimento de } \\
\text { rotina de relaxamento, com } \\
\text { diminuição dos estímulos } \\
\text { aplicados a partir de certo } \\
\text { horário, adotando medidas } \\
\text { como o banho morno e dietas } \\
\text { leves a partir do período } \\
\text { noturno. }\end{array}$ \\
\hline $\begin{array}{l}\text { Desenvolvi- } \\
\text { mento. }\end{array}$ & $\begin{array}{l}\text { Risco de de- } \\
\text { senvolvimen- } \\
\text {-to atrasado. }\end{array}$ & $\begin{array}{l}\text { Relacionado } \\
\text { ao distúrbio } \\
\text { genético. }\end{array}$ & & $\begin{array}{l}\text { 1. Aplicar a curva de } \\
\text { neurodesenvolvimento, } \\
\text { considerando a presença da } \\
\text { síndrome; } \\
\text { 2. Associar o cuidado de saúde } \\
\text { ao âmbito escolar, formulando } \\
\text { parceria com o centro de } \\
\text { educação para acompanhar o } \\
\text { desenvolvimento neurológico } \\
\text { quanto ao aprendizado; } \\
\text { 3. Sugerir aos responsáveis } \\
\text { manter uma rotina de } \\
\text { estimulação com atividades } \\
\text { físicas e recreativas coerentes } \\
\text { com os limites estabelecidos } \\
\text { pela síndrome a fim de } \\
\text { proporcionar melhora da } \\
\text { interação com o meio e } \\
\text { consequente desenvolvimento } \\
\text { psicomotor. }\end{array}$ \\
\hline $\begin{array}{l}\text { Respostas } \\
\text { cardiovas- } \\
\text { culares/pul- } \\
\text { monares. }\end{array}$ & $\begin{array}{l}\text { Padrão } \\
\text { respiratório } \\
\text { ineficaz. }\end{array}$ & $\begin{array}{l}\text { Relacionado } \\
\text { à } \\
\text { hipertensão } \\
\text { pulmonar. }\end{array}$ & $\begin{array}{l}\text { Evidenciado } \\
\text { por dispneia. }\end{array}$ & $\begin{array}{l}\text { 1. Reforçar a necessidade da } \\
\text { administração contínua } \\
\text { e adequada conforme a } \\
\text { prescrição médica do anti- } \\
\text { hipertensivo Enalapril; } \\
\text { 2. Orientar a criança a reconhecer } \\
\text { sua necessidade de momentos } \\
\text { de repouso. }\end{array}$ \\
\hline $\begin{array}{c}\text { Lesão } \\
\text { periférica. }\end{array}$ & $\begin{array}{l}\text { Risco de } \\
\text { disfunção } \\
\text { neurovascular } \\
\text { periférica. } \\
\end{array}$ & $\begin{array}{l}\text { Relacionado } \\
\text { à obstrução } \\
\text { vascular. }\end{array}$ & & $\begin{array}{l}\text { 1. Manter extremidades } \\
\text { aquecidas e pele hidratada } \\
\text { constantemente. }\end{array}$ \\
\hline
\end{tabular}




\begin{tabular}{|c|c|c|c|}
\hline $\begin{array}{l}\text { Respostas } \\
\text { cardiovas- } \\
\text { culares/pul- } \\
\text { monares. }\end{array}$ & $\begin{array}{l}\text { Risco de } \\
\text { função } \\
\text { cardiológica } \\
\text { prejudicada. }\end{array}$ & $\begin{array}{l}\text { Relacionado } \\
\text { à estenose } \\
\text { aórtica- } \\
\text { supravalvar. }\end{array}$ & $\begin{array}{l}\text { 1. Explicar os sinais de } \\
\text { acometimento do sistema } \\
\text { cardiopulmonar relacionados } \\
\text { à síndrome; } \\
\text { 2. Orientar necessidade de } \\
\text { avaliação periódica com o } \\
\text { clínico pertinente ao caso. }\end{array}$ \\
\hline $\begin{array}{l}\text { Papéis do } \\
\text { cuidador. }\end{array}$ & $\begin{array}{l}\text { Risco de } \\
\text { tensão do } \\
\text { papel do } \\
\text { cuidador. }\end{array}$ & $\begin{array}{l}\text { Relacionado } \\
\text { à gravidade } \\
\text { da doença } \\
\text { do receptor } \\
\text { de cuidados. }\end{array}$ & $\begin{array}{l}\text { 1. Vincular os cuidados à grupos } \\
\text { de apoio ou associações que } \\
\text { atendam a Síndrome; } \\
\text { 2. Encaminhar ao serviço de } \\
\text { psicologia se necessário. }\end{array}$ \\
\hline
\end{tabular}

Fonte: Dados do estudo (2020).

\section{CONSIDERAÇÕES FINAIS}

Ao término deste estudo, conclui-se que o acompanhamento de puericultura pelo enfermeiro e equipe interdisciplinar, torna-se de suma importância no contexto da atenção primária, pois compreende a atenção integral à criança, atentando-se para todas as fases do desenvolvimento e suas particularidades, avaliando peso, altura, fatores físicos, cognitivos e psicossociais.

Por meio desta monitorização torna-se possível identificar fatores que indiquem alteração nesse processo de desenvolvimento, bem como patologias pré-existentes ou síndromes, favorecendo assim um diagnóstico precoce e consequentemente intervenções mais efetivas, com o intuito de contribuir com a diminuição de complicações relacionados a patologia identificada e dar continuidade na promoção de saúde para a criança e família.

\section{REFERÊNCIAS}

ALKHOLY, Usama M.; et al. Vascular endothelial growth factor and pulmonary hypertension in children with beta thalassemia major. Jornal de Pediatria, Porto Alegre, v.95, n. 5, p. 593-599, sept. 2019. Disponível em: http:/ /www.scielo.br/scielo. php?script=sci_arttext\&pid=S0021-75572019000600593\&lng=en\&nrm=iso. Acesso em: 29 abr. 2020.

\section{BARAK, Boaz; et al. Neuronal Deletion of Gtf2i, Associated With Williams} Syndrome, Causes Behavioral and Myelin Alterations Rescuable by a Remyelinating Drug. Nature Neuroscience, v.22, n.5, p.700-708, may. 2019. Disponível em: https:/ / pubmed.ncbi.nlm.nih.gov/31011227/. Acesso em: 29 abr. 2020.

BELO, Wanessa Alves; OSELAME, Gleidson Brandão; NEVES, Eduardo Borba. Clinical and hospital profile of children with congenital heart disease. Cadernos Saúde Coletiva, Rio de Janeiro, v.24, n.2, p.216-220, jun. 2016. Disponível em: http:/ / 
www.scielo.br/scielo.php?script=sci_arttext\&pid=S1414-462X2016000200216\&lng=en \&nrm=iso. Acesso em: 29 abr. 2020.

CALDERARO, Daniela; et al. Pulmonary Hypertension in General Cardiology Practice. Arquivos Brasileiros de Cardiologia, São Paulo, v.113, n.3, p.419-428, sept. 2019. Disponível em: http:/ / www.scielo.br/scielo.php?script=sci_arttext\&pid=S0066782X2019000900419\&lng=en\&nrm=iso. Acesso em: 29 abr. 2020.

COELHO, Renato; et al. Child development in primary care: a surveillance Proposal. Jornal de Pediatria, Porto Alegre, v.92, n.5, p.505-511, oct. 2016. Disponível em: http:/ / www.scielo.br/scielo.php?script=sci_arttext\&pid=S0021-75572016000600505\&lng=en \&nrm=iso. Acesso em: 27 mar. 2020.

CORREA, Wesley; MINETTO, Maria de Fatima; CREPALDI, Maria Aparecida. Família como promotora do desenvolvimento de crianças que apresentam atrasos. Pensando famílias, Porto Alegre, v.22, n.1, p.44-58, jun. 2018. Disponível em: http:/ / pepsic.bvsalud.org/scielo.php?script=sci_arttext\&pid=S1679-494X2018000100005\&lng =pt\&nrm=iso. Acesso em: 27 mar. 2020.

CRUZ, Renata Cristina Castro; et al. Predictors of Unfavourable Outcomes in Children and Adolescents Submitted to Surgical Mitral Valvuloplasty Secondary to Chronic Rheumatic Heart Disease. Arquivos Brasileiros de Cardiologia, São Paulo, v.113, n.4, p.748-756, oct. 2019Disponível em: http:/ / www.scielo.br/scielo. php?script=sci_arttext\&pid=S0066-782X2019001000748\&lng=en\&nrm=iso. Acesso em: 29 abr. 2020.

DORNELAS, Lílian de Fátima; MAGALHAES, Lívia de Castro. Functional performance of school children diagnosed with developmental delay up to two years of age. Revista Paulista de Pediatria, São Paulo, v.34, n.1, p.78-85, mar. 2016. Disponível em: http:/ / www.scielo.br/scielo.php?script=sci_arttext\&pid=S010305822016000100078\&lng=en\&nrm=iso. Acesso em: 27 mar. 2020.

FRICKE, Tyson A; et al. Surgical repair of supravalvular aortic stenosis in children with williams syndrome: a 30-year experience. The Annals of thoracic surgery, v.99, n.4, p.1335-41, 2015. Disponível em: https:/ / pubmed.ncbi.nlm.nih.gov/25661907/. Acesso em: 29 abr. 2020.

GUENAT, David; et al. DNA damage response defect in Williams-Beuren syndrome. International Journal of Molecular Medicine, n.39, v.3, p.622-628, 2017. Disponível em: https:/ / www.ncbi.nlm.nih.gov/pmc/articles/PMC5360356/. Acesso em: 29 abr. 2020 .

GHAFFARI, Mahsa; et al. Genotype-phenotype Correlation and the Size of Microdeletion or Microduplication of 7q11.23 Region in Patients With WilliamsBeuren Syndrome. Annals of Human Genetics, n.82, v.6, p.469-476, nov. 2018. Disponível em: https:/ / pubmed.ncbi.nlm.nih.gov/30155880/. Acesso em: 29 abr. 2020. 
KATTAN, Javier; et al. Neonatal and Pediatric Extracorporeal Membrane Oxygenation in Developing Latin American Countries. Jornal de Pediatria, Porto Alegre, v.93, n.2, p.120-129, apr. 2017. Disponível em: https:/ /www.ncbi.nlm.nih. gov/pubmed/28034729. Acesso em: 14 mai. 2020.

LIMA, Marcela Silva; et al. Pulmonary hypertension evaluation by Doppler echocardiogram in children and adolescents with mouth breathing syndrome. Brazilian Journal of Otorhinolaryngology, São Paulo, v.83, n.3, p.292-298, jun. 2017. Disponível em: http:/ / www.scielo.br/scielo.php?script=sci_arttext\&pid=S180886942017000300292\&lng=en\&nrm=iso. Acesso em: 29 abr. 2020.

MATOS, Larissa Araújo; CAVALCANTE, Lília Iêda Chaves; COSTA, Elson Ferreira. Características do ambiente sociofamiliar e desenvolvimento neuropsicomotor de crianças: associações e implicações. Revista Subjetividades, Fortaleza, v.16, n.3, p.97-108, dez. 2016. Disponível em: http:/ / pepsic.bvsalud.org/scielo.php?script=sci_ arttext\&pid=S2359-07692016000300008\&lng=pt\&nrm=iso. Acesso em: 27 mar. 2020.

MENDES, Karina Dal Sasso; SILVEIRA, Renata Cristina de Campos Pereira; GALVAO, Cristina Maria. USO DE GERENCIADOR DE REFERÊNCIAS BIBLIOGRÁFICAS NA SELEÇÃO DOS ESTUDOS PRIMÁRIOS EM REVISÃO

INTEGRATIVA. Revista Texto e Contexto Enfermagem, Florianópolis, v.28, e20170204, 2019. Disponível em: http:/ /www.scielo.br/scielo.php?script=sci_ arttext\&pid=S0104-07072019000100602\&lng=en\&nrm=iso. Acesso em: 29 abr. 2020.

MURAMATSU, Yukako; et al. Disparities in Visuo-Spatial Constructive Abilities in Williams Syndrome Patients With Typical Deletion on Chromosome 7q11.23. Brain and Development, n.39, v.2, p.145-153, feb. 2017. Disponível em: https:// pubmed. ncbi.nlm.nih.gov/27692871/. Acesso em: 29 abr. 2020.

NANDA INTERNATIONAL. Diagnósticos de enfermagem da NANDA-I: definições e classificação 2018-2020. 11.ed. Porto Alegre: Artmed, 2018.

OSÓRIO, Ana A. C.; et al. Psychopathology and Behavior Problems in Children and Adolescents With Williams Syndrome: Distinctive Relationships With Cognition. Child Neuropsychology, n.23, v.6, p.631-641, 2016. Disponível em: https:// pubmed. ncbi.nlm.nih.gov/27224940/. Acesso em: 29 abr. 2020.

PAZELLO, João Arthur; CAMAROZANO, Ana Cristina. Correlation between degrees of pulmonary hypertension and findings in complementary tests. Arquivos Brasileiros de Cardiologia: Imagem Cardiovascular, v.31, n.3, p,175-182, 2018. Disponível em: https:/ / pesquisa.bvsalud.org/portal/resource/pt/biblio-909414. Acesso em: 29 abr. 2020.

PLÁCIDO, Rui; et al. Estratificação prognóstica na hipertensão pulmonar: valor acrescido da abordagem multibiomarcadores. Revista Portuguesa de Cardiologia, v.36, n.2, p.111-125, 2017. Disponível em: https:/ / www.revportcardiol.org/ptestratificacao-prognostica-na-hipertensao-pulmonar-articulo-S0870255116302153. Acesso em: 29 abr. 2020. 
PRADO, Marta Lenise do; et al. Arco de Charles Maguerez: refletindo estratégias de metodologia ativa na formação de profissionais de saúde. Escola Anna Nery, Rio de Janeiro, v.16, n.1, p.172-177, mar. 2012. Disponível em: http:/ /www.scielo.br/scielo. php?script=sci_arttext\&pid=S1414-81452012000100023\&lng=en\&nrm=iso. Acesso em: 29 abr. 2020.

REIS, Abílio; et al. Disability and its clinical correlates in pulmonary hypertension measured through the World Health Organization Disability Assessment Schedule 2.0: a prospective, observational study. J. bras. pneumol. São Paulo, v.45, n.4, e20170355, 2019. Disponível em: http:/ / www.scielo.br/scielo.php?script=sci_ arttext\&pid=S1806-37132019000400205\&lng=en\&nrm=iso. Acesso em: 29 abr. 2020.

SANTOS, Mário; et al. Long-term Survival in Pulmonary Arterial Hypertension and Chronic Thromboembolic Pulmonary Hypertension: Insights From a Referral Center in Portugal. Revista Portuguesa de Cardiologia, v.37, n.9, p.749-757, sep. 2018. Disponível em: https:/ / pubmed.ncbi.nlm.nih.gov/30144959/. Acesso em: 29 abr. 2020.

SILVA, Evair Barreto da; et al. Mapping of nursing activities related to diagnosis: delayed growth and development. Revista Rene, Fortaleza, v.18, n.2, p.234-241, abr. 2017. Disponível em: http:/ / www.revenf.bvs.br/scielo.php?script=sci_ arttext\&pid=S1517-38522017000200234\&lng=pt\&nrm=iso. Acesso em: 27 mar. 2020.

SOARES, Ana Ravenna Sales; et al. Avaliação do desenvolvimento neuropsicomotor em crianças de 0-18 meses acompanhadas em uma Unidade Básica de Saúde da Família. Revista Saúde e Pesquisa, Maringá (PR), v.10, n.3, p.531-538, set./dez. 2017. Disponível em: https:/ / periodicos.unicesumar.edu.br/index.php/saudpesq/article/ view /6221. Acesso em: 27 mar. 2020.

SZAFLIK, Katarzyna; et al. Severe Congenital Obstruction of the Left Main Coronary Artery Coexisting With Supravalvular Aortic Stenosis in Williams Syndrome:

A Dangerous Association. World Journal for Pediatric and Congenital Heart Surgery, v.7, n.2, p.216-9, mar. 2016. Disponível em: https:/ / pubmed.ncbi.nlm.nih. gov/26582765/. Acesso em: 28 abr. 2020.

TORRES, Diego de Faria Magalhães; et al. Association Between Hemodynamic Profile, Physical Capacity and Quality of Life in Pulmonary Hypertension.

Arquivos brasileiros de cardiologia, v.104, n.5, p.387-93, 2015. Disponível em: https:/ / pubmed.ncbi.nlm.nih.gov/25742419/. Acesso em: 29 abr. 2020.

YAO, Dan; et al. Physical growth and development characteristics of children with Williams syndrome aged 0-24 months in Zhejiang Province. Journal of Pediatric Endocrinology and Metabolism, v.32, n.3, p.233-237, 2019. Disponível em: https:/ / pubmed.ncbi.nlm.nih.gov/30710484/. Acesso em: 29 abr. 2020.

YILDIZ, Okan, et al. Left Coronary Artery Stenosis Causing Left Ventricular Dysfunction In Two Children With Supravalvular Aortic Stenosis. World Journal for Pediatric and Congenital Heart Surgery, v.6, n.2, p.311-316, 2015. Disponível em: https:/ / pubmed.ncbi.nlm.nih.gov/25870356/. Acesso em 29. Abr. 2020. 
ZAGO, Jéssica Teixeira de Carvalho; et al. Association between neuropsychomotor development and biological and environmental risk factors in early

childhood children. Revista CEFAC, São Paulo, v.19, n.3, p.320-329, jun. 2017.

Disponível em: http:/ / www.scielo.br/scielo.php?script=sci_arttext\&pid=S151618462017000300320\&lng=en\&nrm=iso. Acesso em: 27 mar. 2020. 